\title{
LOS ESTUDIOS DE LA CULTURA EN LATINOAMÉRICA Y LA CRISIS DE LA CRÍTICA LITERARIA
}

\author{
GENARA PULIDO TIRADO \\ Universidad de Jaén
}

\section{Resumen:}

El incremento de los estudios sobre la cultura, que tenían una larga tradición en Latinoamérica, contribuye a aumentar la crisis que se venía detectando en los estudios literarios desde mediados del siglo XX, crisis producida por factores de carácter social, político, económico e histórico, pero también literario: la necesidad de crear instrumentos operativos y propios con los que poder dar cuenta de una producción literaria propia que, a partir del boom, adquiere una marcada resonancia internacional. La aparición de los estudios culturales latinoamericanos produce un desplazamiento de intelectuales que, procedentes en muchos casos del ámbito crítico y teórico literario, ven en esta moda emergente más posibilidades para desarrollarse profesionalmente. Pero los estudios literarios no desaparecen sino que, por el contrario, se sumergen en un profundo y largo proceso de revisión crítica que tiene por objeto adaptarse a una nueva realidad. Esta revisión, impregnada de un profundo pesimismo en un primer momento, va a ser muy positiva a largo plazo ya que la teoría literaria latinoamericana se constituye, y lo hace además con mayor rigor y conciencia crítica que en otros ámbitos geográficos.

Palabras clave: Estudios culturales, cultural studies anglonorteamericanos, estudios literarios, teoría crítica, prácticas intelectuales en cultura y poder, valor estético, función del intelectual, alta cultura, cultura popular y cultura de masas.

\begin{abstract}
:
The increase in the amount of studies on culture, which have had a long tradition in Latin America, has contributed to deepening the crisis which was becoming evident in literary studies from the mid-twentieth century onwards, a crisis stemming from social, political, economic and historical factors, but also from literary factors: the need to create their own suitable instruments to account for their own literary output, which after the LatinAmerican boom acquired a marked international impact. The appearance of Latin American cultural studies has brought about a displacement of intellectuals who, coming from critical and theoretical-literary domains, see in this emerging fashion more possibilities for their own professional development. But literary studies have not disappeared; on the contrary, they are undergoing a deep and long process of critical revision with an aim to their adapting to a new reality. This revision, at first pervaded by a deep pessimism, in the long run will be very positive, since, Latin American literary theory is in the process of being constituted and is doing so with a more rigorous and critical awareness than in other geographical areas.
\end{abstract}

Key words: Cultural studies, Anglo-American cultural studies, literary studies, critical theory, intellectual practices in culture and power, aesthetic value, role of the intellectual, highbrow culture, popular culture and culture of the masses. 


\title{
1. La cultura como objeto y como problemática: el surgimiento de los estudios culturales
}

partir de un determinado momento histórico, la segunda mitad del
siglo XX, en América Latina no pudo ignorarse el ámbito
transnacional en el que toda sociedad tiene un punto de referencia obligado, y con el auge de un determinado neoliberalismo llega el incremento del consumo, la ruptura total entre baja y alta cultura, el surgimiento de nuevas teorías críticas como el postestructuralismo, la desconstrucción o la teoría crítica feminista, la crisis del marxismo tradicional, el surgimiento de nuevos movimientos sociales, y un largo etcétera.

Esta profunda crisis ya había sido constatada desde la metrópoli por Hernán Vidal quien, al tiempo que señalaba el problema, ofrecía una solución:

\begin{abstract}
[la] crítica literaria se encuentra en un momento crucial de su historia: la tradición de canonizar y privilegiar ciertos textos de la alta cultura oficial como instrumentos fundamentales en la creación de las identidades nacionales no tiene sentido frente a los efectos de una industria cultural. Ante eso, el único camino abierto para la renovación es que la crítica literaria... dé el paso definitivo de constituirse en y reconocerse como una crítica de la cultura (Vidal, 1993c: 37).
\end{abstract}

Este crítico ya había propuesto una década antes "una redefinición culturalista de la crítica literaria latinoamericana" (1983) en un número monográfico de Ideologies and Literature dedicado a El significado socio-político de la crítica actual (España, Portugal, Latinoamérica, Luso-África) que recogía las ponencias de un encuentro internacional. En la "Introducción" al volumen el balance que realiza el editor es sumamente significativo:

\begin{abstract}
Al cerrar este esbozo general, es preciso consignar la tendencia más innovadora observada en la conferencia. Ella se decanta a partir de esfuerzos por responder a la problemática creada por la transnacionalización de la economía capitalista y su secuela de migraciones y exilios masivos. La tendencia que mencionamos busca explorar aspectos de la experiencia social previos y posteriores a su formalización en géneros y textos literarios o el consumo de ellos. Para ello se propone el estudio sistemático de la cotidianidad en las sociedades capitalistas como espacio generador de significaciones que ideológicamente constituyen a individuos y grupos en actores interpretativos de cultura y productos de ella (Vidal, 1983a: 5).
\end{abstract}

He aquí la descripción del proceso que lleva a la crítica socio-histórica o marxista de la literatura a una crítica de la cultura de izquierdas, de la que el mismo Hernán Vidal es un buen representante. La explicación histórica de esta situación se busca en el surgimiento de estados autoritarios en Chile, Uruguay y Argentina en los años setenta y, lógicamente, la implantación en Cuba de un estado socialista tras la Revolución cubana:

En esta experimentación se ha producido una conciencia cada vez más aguda de que, para solucionar los problemas de conexión de la intratextualidad literaria con su contexto social, es indispensable una fundamentación argumentada en una teoría de la producción de la cultura. Sólo así es posible situar un texto literario en el proceso de su gestación e impacto en una sociedad específica. De este modo, se 
puede postular razonablemente la relación de un texto literario con los diversos grupos-agentes sociales que buscan orientar, modificar el desarrollo de la sociedad (Vidal, 1983b: 122).

La consecuencia más directa de este cambio de coordenadas es que el crítico literario termina convirtiéndose en culturólogo. Es lo que podemos observar en la obra colectiva Hermenéuticas de lo popular (1993) que edita Hernán Vidal, donde este autor traza las coordenadas de los nuevos intereses culturales (que no crítico o teórico literarios): la religión y la teología de la liberación, y la consideración del otro que desemboca en los estudios subalternos y el indigenismo. El objetivo es expuesto en la "Introducción":

Esta edición presenta trabajos que buscan afirmar los estudios culturales latinoamericanos como una opción más de la investigación y enseñanza dentro de los departamentos universitarios de literaturas hispánicas. Entendemos por estudios culturales la tarea de captar, analizar e interpretar procesos de apropiación y creación de sistemas simbólicos en la cotidianidad, en el marco de una estructura de poder hegemónico (Vidal, 1993c: 7).

Y es que, como ha señalado después Román de la Campa, "esta vuelta a la cultura brotaba de la propia vanguardia crítico-literaria" (2003: 356) que de esta manera desarrollaba sus posibilidades de articulación más allá de los estudios literarios y del ámbito nacional que normalmente conservaba este estatuto disciplinario para pasar a tratar temas como el feminismo, las artes o el discurso de las dictaduras ${ }^{1}$. Además, la cultura misma no es ajena a una situación de crisis y cambios:

Se dice que la cultura se ha vuelto omnipresente, aunque no esté claro si ello implica una diseminación o una disolución de las formas artísticas que la nutren. En cualquier caso, esa misma indeterminación asume la condición fronteriza de todo intelectual, ya que hacer crítica hoy día implica permutar, transitar, o viajar entre espacios inciertos y a veces efímeros (Campa, 1996: 715).

Pero es que, además, el desprestigio sufrido por la literatura como institución, al que habrían contribuido el postestructuralismo, la sociocrítica o la desconstrucción, ha sido aprovechado por la crítica cultural. Como señala Jean Franco, "no se trata únicamente de la apropiación de la cultura popular por los autores cultos [...] sino [...] del carácter flexible de las culturas populares que desafían cualquier intento de totalización o institucionalización" (1994-1995: 16); ante tal situación sólo cabe crear una nueva crítica literaria que atienda tanto al fin de un ciclo literario como a una nueva manera de entender la historia literaria.

\footnotetext{
${ }^{1}$ No menos importante es el hecho señalado por Mariaca (1994-1995: 158) de que "Para los fundadores de la crítica literaria la obsesión era salvar a América por la cultura, es decir, por la homogeneidad discursiva de alguna modernidad cultural", de donde se deduce que la semilla de la discordia estaba presente desde el principio, en autores como Henríquez Ureña o Alfonso Reyes, y aún antes.
} 
En efecto, Latinoamérica tiene una amplia tradición de estudios que se inscriben en el ámbito de la crítica cultural. William Rowe (1994-1995) estudia dos tradiciones de crítica cultural nacidas, respectivamente, en Argentina y Perú. En ambos casos se trata, sobre todo, de indagar en las viejas culturas de los países latinoamericanos en un intento de determinar la propia especificidad -y establecer, desde un ámbito propio, en qué pueda consistir su identidad-, hecho que nunca ha dejado de preocupar en este ámbito geográfico y cultural por las razones de colonización y superposición de culturas que todos conocemos. Es lógico, por otra parte, que la dialéctica entre lo local y lo transnacional adquiera aquí una importancia muy destacada. Pero lo que resulta evidente es que esos estudios de crítica cultural, aunque constituyen un sustrato importante que sigue actuando, no son siempre el tipo de estudios que se preconiza y se demanda desde el presente. Por otra parte, de forma paralela a los cambios operados en lo literario, el término cultura se está desestabilizando, por lo que conviene atender a las advertencias de Rowe:

\begin{abstract}
La crítica cultural, frase poco oída hace cinco años, se está convirtiendo en una nueva moda intelectual. Pero la presente aceptación de la crítica cultural conlleva el peligro de que se la considere simplemente una puesta al día de las prácticas anteriormente existentes, mediante su extensión a nuevos objetos de estudio. La crítica literaria comienza a abarcar las culturas populares, la sociología aprende a apreciar los textos culturales, los historiadores hacen lecturas de textos estéticos. Todo esto es un hecho, un hecho obviamente valioso. Pero definirlo así corre el riesgo de dejar fuera lo más importante: que la nueva importancia de la reflexión sobre la cultura no solo obedece a cambios de relación entre las disciplinas en el campo intelectual, sino que obedece a una crisis que ha sacudido a las bases de la socialidad, la política, la cultura (Rowe, 1994-1995: 42).
\end{abstract}

Y es que, como habría de observar años después Catherine Walsh (2003: 23): "en América Latina, todavía se confunden los estudios sobre la cultura con los estudios culturales". Buen ejemplo de ello es que representantes destacados de los estudios culturales latinoamericanos no han dudado en afirmar: "Nosotros ya habíamos hecho estudios culturales mucho antes de que esta etiqueta apareciera", declaración que realiza Martín Barbero en una entrevista que le realiza Ellen Spielmann (1996). En esta entrevista el autor hispano empieza por cuestionar los supuestos beneficios de la modernidad en América Latina ya que a su juicio la razón instrumental de la Ilustración no tiene en Latinoamérica ningún poder liberador ni de desarrollo puesto que la expansión del capitalismo produce divisiones y miserias hasta que en los años cuarenta la modernidad se convierte en un hecho colectivo y social y a partir de los años cincuenta y sesenta se produce la secularización, la separación Iglesia / Estado, que permite que exista un cierto mercado de la cultura. El fracaso de los proyectos de izquierda de los años sesenta y setenta y el exilio de numerosos intelectuales del subcontinente (el desplazamiento de chilenos, argentinos y brasileños hacia países del norte como Colombia, Venezuela y México es fundamental ya que llevan consigo ideas del pensamiento europeo que se habían dado a conocer en los países del sur) marcan todo el proceso, lo que no 
impide que los intelectuales del momento, entre ellos los ligados a los medios de comunicación, cambien sus planteamientos básicos:

\begin{abstract}
Empezamos a trabajar esa idea: el proceso de comunicación implica actividad de lado del receptor, no pura reacción a un estímulo, la visión behaviorista. Empezaron a valorarse en la historia nacional ciertas especificidades nacionales y con esta actividad de receptor empezó una nueva relación con las culturas populares. Empezamos a ver que las culturas populares no son simplemente para conservar, sino algo que tiene que ver con el futuro. Empezamos a estudiar la historia y encontramos relaciones de lo masivo que realmente habían estado presentes en montones de producciones de los medios desde los años 20/30, en los cuales había incorporación de cultura popular que pasa por el cine, por la imprenta, por la radio. Lo fundamental es: se rompió la división puramente maniquea: lo masivo vs. lo popular, lo masivo vs. lo culto. Empezamos a ver una transfusión continua de matrices (apud Spielmann, 1996: 4).
\end{abstract}

Es incuestionable que la cultura se ha puesto de moda en todo el mundo occidental, pero el objetivo no es ya únicamente el estudio de las culturas tradicionales que pueden contribuir a plasmar la identidad actual de una nación-estado (estudio que, por otra parte, siguen realizando disciplinas como la antropología o la etnografía). El mundo ha cambiado y, en consecuencia, la cultura y el estudio de la cultura no pueden permanecer anclados en el pasado.

No es extraño, en este sentido, que uno de los más destacados estudiosos de la teoría y crítica de la cultura en Latinoamérica, Néstor García Canclini, haya señalado dos procesos que determinan la desestabilización misma que afecta al concepto de cultura: la descolección y la desterritorialización. En efecto, ha pasado ya la época en la que tener una identidad era pertenecer a un país, una ciudad o un barrio, una entidad donde la identidad básica se compartía con aquellos que habitaban en ese lugar; en la época de la transnacionalización de las comunicaciones y las migraciones multidireccionales este modelo se muestra caduco y hay que recurrir a conceptos más operativos, como el de transculturación que ofrece el mismo crítico afincado en México.

La cuestión es, en palabras de Rowe (1994-1995: 45), que "la necesidad de imaginar un nuevo estado, no basado en la modernidad etnocida, se encuentra con el problema de cómo combinar la pluralidad cultural con la racionalidad organizativa". Y para responder a esta necesidad acuciante no disponemos ya de las viejas disciplinas académicas puesto que éstas también han sufrido el desplazamiento y la desterritorialización histórica de sus respectivos objetos de estudio, lo que ha desembocado en el cuestionamiento y la crisis.

A principios de la década de los noventa el mismo García Canclini se pregunta:

¿Por qué existen tantas disciplinas para estudiar la cultura? La hipótesis de partida de este texto es que la proliferación de tendencias es efecto de problemas no resueltos en la investigación, los cuales dificultan construir un modelo teórico y un conjunto coherente de estrategias de conocimientos ampliamente compartidos. Las divergencias también derivan de las condiciones sociopolíticas y las tradiciones institucionales separadas en que se practican las ciencias sociales (García Canclini, 1991: 8). 
Este autor nota cómo se van afianzado los estudios sociológicos de la cultura y los antropológicos sobre la modernización cultural en este ámbito. Consciente ya de formar parte de los estudios culturales, aunque sin negar la rica tradición cultural existente en México, Canclini ofrece una definición de cultura que pretende que sea operativa en tanto que su concepto goza de amplio consenso internacional: "la cultura como el ámbito de producción, circulación y consumo de significaciones "(1991: 18). Pero el consenso no puede evitar que lo cultural se vea determinado por la reestructuración neoliberal que se estaba produciendo en las sociedades de Latinoamérica así como por la necesidad de articular lo tradicional y lo moderno en el ámbito cultural, hecho que da lugar al conocido concepto de culturas híbridas: "La tarea del investigador no puede ser elegir entre tradición y modernidad. Más bien se trata de entender por qué en América Latina somos esta mezcla de memorias heterogéneas e innovaciones truncas" (1991.: 24).

Carlos Rincón ha visto las derivaciones que han tenido los estudios culturales en este contexto marcado por los cambios:

\begin{abstract}
La redefinición metodológica transdisciplinaria -el cambio de paradigmas- y el proceso de Remapping culture, para emplear la fórmula de Jean Franco, a que ha dado lugar, se han cumplido paralelamente a las recientes formulaciones culturales por parte de las ciencias sociales "duras" y de las ciencias de la comunicación y de los medios, cuando han intentado dar cuenta de las tensiones entre lo global y lo local. Estas teorizaciones se concentran en los nuevos procesos de hibridación cultural en las márgenes de las culturas populares y de la erudita o en situaciones de frontera, sobre las dinámicas de desterritorialización [...], y en la oralidad secundaria de las nuevas culturas urbanas del subcontinente. En la doble perspectiva así bosquejada, propia de los Estudios culturales, la cultura resulta red de discursos sociales con función ordenadora y lucha por el poder interpretativo, a la vez que se produce una redefinición, en términos culturales, de la crítica (Rincón, 1994-1995: 8).
\end{abstract}

Y la primera consecuencia de esta redefinición es la irrupción de la problemática del canon literario, problemática que el mismo crítico había tratado en una obra anterior (Rincón, 1978), pero también la necesidad de estudio de formas marginales y de carácter oral, la ubicación territorial de la enunciación crítica y la renovación epistemológica (ser capaces de revisar los viejos métodos y, en función de las nuevas necesidades de conocimiento, buscar nuevas formas de aprehender objetos de estudio complejos y cambiantes).

El cambio operado en América Latina a lo largo del siglo XX es realmente importante. La literatura a finales del siglo XIX y principios del XX cumple una función fundamental en la construcción de la esfera pública moderna. Surge la cuestión de la literatura nacional en torno a la cual se agrupan propuestas en relación a la identidad nacional, las políticas estatales sobre inmigración y minorías étnicas o distintos proyectos educativos. La literatura y la crítica literaria son también socialmente significativas en torno a la teoría y la práctica de la Revolución. No es extraño, en este sentido, que algunos autores atribuyan la crisis de esta práctica a la caída de la vanguardia política revolucionaria. No olvidemos que debates tan importantes como el que se estableció en torno al 
concepto de Barroco literario en América Latina ponen de manifiesto la centralidad de la práctica literaria en la escena social.

Será tras la caída de las dictaduras, y en plena transición democrática, cuando los estudios culturales tomarán el poder aprovechándose de hechos tan destacados como la aparición e implantación de los medios audiovisuales, populares, para las masas, medios portadores de discursos cuya recepción exige menos esfuerzo. En este punto es significativo el olvido que la aldea global muestra en relación a los estudios culturales latinoamericanos que, no ajenos a la necesidad de promoción, han producido su propia etiqueta para el mercado transnacional, Latin American Cultural Studies -con su correspondiente asociación Latin America Cultural Studies Association-LASA, y su revista, Travesía. A Journal of Latin American Cultural Studies, publicada en Londres-, etiqueta que, a pesar de los múltiples y reiterados intentos de marcar distancias en relación a la vieja y nueva metrópoli (Europa, con los Cultural Studies británicos, y Norteamérica, con los nuevos cultural studies), tiene una concreta razón de ser ya que en las universidades norteamericanas, sobre todo en torno a los Departamentos de Literatura Iberoamericana o de Lenguas Española y Portuguesa, los jóvenes latinoamericanos encuentran el apoyo y las oportunidades que no tienen en sus respectivos países de origen, por lo que la emigración se produce con mucha frecuencia ${ }^{2}$. Sin embargo, vistos desde América Latina -aunque esta autora desarrolle su labor académica en Estados Unidos-, Alicia Ríos define los estudios culturales de forma más amplia y cabal:

Los Estudios Culturales Latinoamericanos podrían definirse, muy grosso modo, como un campo de estudios configurado dentro de la tradición crítica latinoamericana (el ensayo de ideas -lo que Julio Ramos ha llamado el "ensayo humanista o secular" - , la teoría de la dependencia y la teología de la liberación), que se mantiene en diálogo constante, muchas veces conflictivo, con las escuelas de pensamiento europeas y norteamericanas (los "Cultural Studies", en sus dos vertientes -inglesa y norteamericana-, el estructuralismo francés, las filosofías posestructuralistas y posmodernas, la sociología de la cultura, la Escuela de Frankfurt, la semiótica, el feminismo y el marxismo) (Ríos, 2002: 1).

Esta relación la expone sin ambages Martín Barbero ya que, aunque sitúa los inicios de sus inquietudes en la lectura de Martí y Arguedas, las lecturas determinantes proceden de autores europeos como Althusser y Gramsci, pero también de los fundadores de los Cultural Studies británicos, esto es, Thompson, Hogart y Williams; además, la formación europea de destacados culturólogos latinoamericanos es muestra significativa al respecto: Néstor García Canclini, Renato Ortiz y Martín-Barbero estudiaron en Francia; García Canclini y Martín-

\footnotetext{
2 La alusión a los estudios culturales latinoamericanos que se producen en los ensayos sobre los estudios culturales en general es reciente y aislada. Uno de los casos en que encuentran mayor acogida y mejor tratamiento es la Introducción a los estudios culturales (2003: 118 y ss.) de Armand Matterlart y Eric Neveu, investigadores que valoran correctamente la importancia que ha tenido el intento de emancipación primero de la hegemonía cultural europea y luego de la estadounidense, así como la presencia de regímenes autoritarios seguidos de difíciles transiciones democráticas en el surgimiento de los estudios culturales en América Latina.
} 
Barbero estudiaron las tesis de Merleau-Ponty; Martín Barbero fue alumno de Paul Ricoeur... Y es que, cuando desaparece el complejo de dependencia imperialista, tampoco se presentan problemas al reconocer el interés de los estudios culturales norteamericanos:

Hay aportes por el estado del estudio sobre nuevas subjetividades. Creo que es muy necesaria esa mirada de género, incluso los márgenes de la sexualidad que son muy importantes, porque la teoría del marxismo no sólo oprimía a la mujer, también a los homosexuales. Yo diría que la relación con los Estados Unidos ahora puede ser muy productiva porque ellos nos aportan ciertos elementos. América Latina no se incorpora a los estudios culturales cuando se pusieron de moda como etiqueta, sino que tienen una historia muy distinta (Martín Barbero, apud Spielmann, 1996: 6).

Pero no es ésta una posición generalizada. En la última década del siglo XX numerosos autores se han encargado de confrontar los estudios culturales practicados en América Latina con los norteamericanos y, en menor medida, con los británicos. Para el Primer Encuentro Interamericano de Estudios Culturales (la Red Interamericana de Estudios Culturales había sido fundada por García Canclini y G. Yúdice), que tuvo lugar en la ciudad de México en 1993, George Yúdice prepara un extenso trabajo, que reelaborará posteriormente, en 2002, intentando articular una serie de cuestiones que en principio marcaban claramente su escepticismo en relación a las posibilidades de acción de los estudios culturales. Yúdice renuncia ahora a establecer una comparación exhaustiva entre ambos espacios discursivos debido a su complejidad, aunque no deja de señalar dos coincidencias notables: el "lugar destacado del marco analítico de lo popular y sus relaciones con la industria cultural y de masas" y "el cambio de definición de cultura" (Yúdice, 2002: 1). En lo que se refiere al concepto de cultura, Yúdice anota el desplazamiento que se ha producido desde una posición elitista a otra cotidiana y antropológica, acorde con la idea de Raymond Williams de "modo de vida integral" 3 . En los años sesenta y setenta se produce un giro hacia el postestructuralismo y el pensamiento de Althusser, que conlleva un primer desplazamiento desde la perspectiva de dominación de las fuerzas económicas y sociales, que serían las que determinarían la conciencia de los grupos dominados, hacia la resistencia que ofrecen estos grupos aun en las circunstancias más adversas. Los ochenta marcan la irrupción de los movimientos de los derechos humanos en centro y sudamérica y la política de representación de los grupos que reivindican su identidad (mujeres, indígenas, negros, etc.).

\footnotetext{
3 Ésta es una de las tres definiciones que da Williams del término "cultura" en sus Keywords (1976). La definición completa es la que sigue: " [la cultura es] un proceso general de desarrollo intelectual, espiritual y estético; un modo de vida particular, referido a un pueblo, un periodo o un grupo; los trabajos y las actividades intelectuales y artísticas" (Williams, 1976, sv.cultura). Hay que decir, en cualquier caso, que el acercamiento a lo cotidiano en García Canclini, como en otros muchos autores latinoamericanos, está más influido por las teorías de Michael de Certeau que de Raymond Williams.
} 
Yúdice inscribe los estudios culturales latinoamericanos en el seno de la tradición ensayística que tanto auge ha tenido en esos países. No hay ningún afán de mantener la etiqueta de estudios culturales por cuanto lo que importa es el estudio de y sobre la cultura, y este estudio, frente a lo que sucede en Estados Unidos, en Latinoamérica se ha realizado con una escasa representación de mujeres, negros e indígenas, y con una presencia importante del intelectual, que ha actuado como sustituto de la sociedad civil al hablar o representar al pueblo y ha actuado además como intermediario entre ese pueblo y el Estado. Por otra parte, las bases de la cultura nacional descansan en lo popular en América Latina:

Esta tradición se remonta a mediados del siglo XIX y se centra en la literatura como medio idóneo para crear una cultura autónoma, independiente de la europea. Andrés Bello, al igual que José Martí, aducía que América Latina no tendría una cultura propia hasta no contar con una literatura claramente definida, basada en prácticas locales que no imitaran modelos europeos. Este impulso autonomista lo retoma Ángel Rama, quien argumenta que ya a fines del diecinueve, con el modernismo literario, la cultura latinoamericana se hallaba a la altura de la europea y la estadounidense (Yúdice, 2002: 3).

La literatura es el fundamento de los estudios literarios nacionales; la raza, el terreno sobre el que se negocia la relación entre nación y Estado en los estudios de cultura popular. Descolonizar y redefinir la propia cultura es el objetivo de toda una tradición de hombres y mujeres latinoamericanos que no siempre son intelectuales puesto que los movimientos sociales desempeñan un papel importante (ya sea contra los regímenes autoritarios o contra la discriminación de la mujer o de determinados grupos étnicos). En definitiva:

La cultura -como campo de lucha entre diversas normas sociales, como producto de mercado, como cruce de estrategias locales, nacionales y transnacionales de acumulación, como intermediación intelectual o activista, como política de identidad, como ética inherente a los movimientos sociales, e inclusive como trascendencia de lo material en los registros estéticos más convencionales- es fundamentalmente un espacio recorrido por procesos de valoración. El valor en los procesos de producción, circulación, recepción, consumo, respuesta, intercambio, etc. es un balón que está en juego en las relaciones de poder, que a su vez arraigan en factores de clase, raza, etnia, género, lugar geopolítico, y otras diferencias culturales (Yúdice, 2002: 5) .

Ni que decir tiene que en ningún momento Yúdice apuesta por la despolitización de la teoría (de la que habla en otro trabajo, v. Yúdice, 2000), tan presente en algunas tendencias de los estudios culturales.

Una posición totalmente distinta es la que representa García Canclini, quien unos años antes apuntaba en otra dirección:

El especialista en cultura gana poco estudiando el mundo desde identidades parciales: ni desde las metrópolis ni desde las naciones periféricas o poscoloniales, ni desde las élites, ni desde los grupos subalternos, ni desde una disciplina aislada, ni desde el saber totalizado. El que realiza estudios culturales habla de las intersecciones (García Canclini, 1995: 10). 
Esta posición implica abogar por una racionalidad que debe ir más allá de las reivindicaciones de grupos concretos, cuyo protagonismo era evidente en esa época en Estados Unidos y en menor medida en América Latina. Esta racionalidad debe dar cuenta de las razones de cada uno y de la estructura de los conflictos y negociaciones, pero lo cierto es que el constructo teórico, para el que se reivindica el lugar de las intersecciones, no es ni desconstructivista ni contestatario desde un punto de vista político. Aunque se cite la oportuna distinción que establece John Beverly (1996) entre conocimiento y acción, acción y actuación, en García Canclini el cambio y la justicia son calificadas de utopías y la situación de los oprimidos y excluidos se atiende sólo como una primera toma de contacto que desaparece en cuanto se adopta la mencionada racionalidad "universalizante". Tenemos, pues, una actitud neoliberal del agrado del vecino del norte. No es extraña la excelente acogida que tuvo la obra fundamental de este autor en Estado Unidos, Culturas híbridas. Estrategias para entrar y salir de la modernidad (1989), que fue traducida al inglés en 1995. El texto que estamos analizando aquí es "El diálogo norte-sur en los estudios culturales", introducción al inglés de Consumidores y ciudadanos: conflictos multiculturales de la globalización (1995), obra en la que la adscripción a la ideología neoliberal que predomina en Estados Unidos es clara. Si bien García Canclini reconoce que América Latina fue "inventada" por Europa en un proceso de conquista y colonización que duró siglos, los vínculos que se producen en el siglo XX con Estados Unidos ya no serían, a su juicio, de carácter colonial o neocolonial:

\begin{abstract}
No puede verse como un simple cambio de amo. Las modificaciones ocurridas mientras se transitaba de la subordinación europea a la norteamericana en los mercados agrícolas, industriales y financieros, en la producción, circulación y consumo de tecnología y cultura, y en los movimientos poblacionales -turistas, migrantes, exiliados- alteraron estructuralmente el carácter de esta dependencia (García Canclini, 1995: 2)
\end{abstract}

Se ignora la diferencia abismal que existe en relación a estas cuestiones entre América del Norte y Centroamérica y América del Sur. El objeto de estudio son las ciudades y las industrias culturales de América Latina, y la tesis central que el ciudadano ha sido desplazado por el consumidor. Ya no son los vínculos sociales ni las funciones del Estado los que marcan las directrices de los hombres, sino el control de corporaciones privadas que determina el consumo $\mathrm{y}$, el consumo "nos hace pensar". Por eso hay que "reconceptualizar el consumo", proceso que pasa por una alta valoración:

Para muchos hombres y mujeres, sobre todo jóvenes, las preguntas propias de los ciudadanos sobre cómo informarnos y quién representa nuestros intereses son correspondidas más por el consumo privado de bienes y de medios de comunicación que por las reglas abstractas de la democracia o por la participación en organizaciones políticas desacreditadas (García Canclini, 1995: 3).

Es evidente que tal situación se produce de hecho, pero su descripción, y lo que es más, su aceptación, ¿pueden contribuir a recomponer las relaciones 
sociales? ¿pueden, por otro lado, terminar con la insatisfacción de la época? Parece que éstos no son objetivos de la actividad culturológica de García Canclini, que en este momento ha eliminado ya cualquier alusión a las artes en tanto que sólo la cultura de masas parece digna de toda consideración y estudio.

Poco tiempo después el culturólogo habla de "el malestar en los estudios culturales", malestar procedente, a su juicio, de de lo que llama "estanflación" (1997: 1), esto es, estancamiento con inflación. La actitud de García Canclini parece ahora contemplar más cuestiones y, en ese sentido, ser más crítica:

\begin{abstract}
Creo que los estudios culturales pueden librarse del riesgo de convertirse en una nueva ortodoxia fascinada por su poder innovador y sus avances en muchas instituciones académicas, en la medida en que encaremos sus puntos teóricos ciegos, trabajemos las inconsistencias epistemológicas a las que nos llevó movernos en las fronteras entre disciplinas y entre culturas, y evitemos "resolver" estas incertidumbres con los eclecticismos apurados o el ensayismo de ocasión a que nos impulsan las condiciones actuales de reproducción "empresarial" del conocimiento y su difusión mercadotécnica. Lo digo así para insinuar que el énfasis teórico epistemológico [...] no puede hacernos olvidar que nuestras incertidumbres están relacionadas con la descomposición del orden social, económico y universitario liberal, con la irrupción y las derrotas de movimientos sociales cuestionados en las últimas décadas y con el desmoronamiento de paradigmas pretendidamente científicos que guiaron la acción social y política (García Canclini, 1997: 3).
\end{abstract}

Esta posición no es, por otra parte, exclusiva de este autor; buena parte de la llamada banda de los cuatro (García Canclini, Martín Barbero, Brunner y Renato Ortiz) ha sido tildada de estar celebrando el mercado o de contemporizar con el mundo capitalista, algo que no preocupa tampoco a Martín-Barbero, quien considera los debates interesantes, aunque no duda en reafirmarse y contestar a las objeciones:

Hay otro tipo de argumentación que es un refugio de la nostalgia -no en el mejor sentido de la palabra-, en el sentido de querer defender cierto mundo en el cual ellos fueron autoridad y tuvieron una pequeña cuota de legitimación y de poder. Esto se desmorona. Yo creo que las cosas son bastante más complejas y que no hay simplemente celebradores del mercado y gente que quiere entrar en el mercado (apud Spielmann, 1996: 4-5).

El consumo, en la teoría de García Canclini, ha tomado el lugar de los mecanismos tradicionales de participación política y es la nueva esfera donde se ejerce la ciudadanía, de manera que tanto la política como la cultura se encuentran subordinadas a la lógica del mercado. La nueva situación implica peligros, pero también posibilidades. García Canclini reconoce que grandes mayorías tienen niveles mínimos de consumo y por lo tanto una participación muy limitada en las nuevas formas de ciudadanía. Nota, por ejemplo, que hay tres niveles de acceso a los medios masivos de comunicación. Mientras las grandes mayorías tienen acceso a la televisión y la radio, sólo una minoría tiene televisión por cable y video, y sólo una elite minúscula usa antenas parabólicas y medios interactivos como el fax, el correo electrónico, e Internet. Tal desigualdad impide ejercer la ciudadanía plena y democráticamente a través 
del consumo, y por eso, argumenta García Canclini, "favorecer el acceso generalizado a las dos últimas modalidades de comunicación es una condición clave para desarrollar formas democráticas actuales de ciudadanía [...]" (1995b: 159). Asegurar las condiciones mínimas para el acceso generalizado al consumo implica una nueva concepción del mercado, "no como simple lugar de intercambio de mercancías sino como parte de interacciones sociales más complejas" (ob. cit.: 53). García Canclini propone, en efecto, refuncionalizar el mercado para que sirva a los intereses de una nueva cultura democrática ${ }^{4}$.

A contrapelo del dogma neoliberal y de las celebraciones posmodernistas de la fragmentación, el culturólogo insiste en que el Estado debe asegurar una participación universal en el consumo y que tiene un papel importante que jugar en la transformación de la función del mercado en las sociedades latinoamericanas.

\section{Cuestionamiento y fragmentación de los estudios culturales en Latinoamérica}

Sin embargo, con la llegada del nuevo milenio, en los países latinoamericanos el estudio de la cultura ha ido agrupándose en torno a unos ejes concretos que han colocado en segundo lugar el marbete de "estudios culturales", por lo menos en teoría ya que en la práctica ha resultado difícil, cuando no imposible. En el año 2000 Isabel Moraña todavía habla del desafío de los estudios culturales en un volumen colectivo, Nuevas perspectivas desde / sobre América Latina: el desafío de los estudios culturales, que recoge las ponencias presentadas al Simposio Internacional que tuvo lugar en el Universidad de Pittsburgh en 1998, junto a otros trabajos realizados por encargo e incluidos después. Moraña reconoce en la "Introducción" a la obra la variedad temática y metodológica que atribuye a los cruces transdisciplinarios que se daban en ese momento en este campo de estudios, campo que no es otro que el de la "crítica de la cultura dentro del campo latinoamericano" (Moraña, 2000: 11), pero una crítica de la cultura sumamente fragmentada y dispersa, como el contenido de la obra, que da una idea de la complejidad de temas y perspectivas que están en juego. La editora lo avisa:

\footnotetext{
Este libro no pretende ofrecer una propuesta única sino aproximaciones parciales y hasta provisionales -a veces contrapuestas- a aspectos muy dispares de la cultura latinoamericana: el de la lectura e incorporación de tradiciones y genealogías en debates actuales, el que vincula problemáticamente cuestiones de clase, raza y género, el que atiende a los tránsitos de la migración y la consecuente reterritorialización de sujetos y prácticas culturales, el que enfoca el lugar de las ideologías en la definición de agendas culturales que se enfrentan al vaciamiento político de la postmodernidad. Se ponen asimismo bajo escrutinio tópicos como
}

\footnotetext{
${ }^{4}$ Sobre la relación de las teorías de García Canclini con la ideología neoliberal, ver Kokotoviv
} (2000). 
nación, identidad y memoria histórica, y problemas vinculados al surgimiento de movimientos sociales en el contexto de la globalidad (Moraña, 2000: 11-12) ${ }^{5}$.

Estas aproximaciones se formulan, como se señala en el mismo título, de y sobre América Latina, pero en realidad son mayoritariamente escritas sobre y desde fuera de América Latina puesto que de las veintiocho aportaciones veintidós proceden de Estados Unidos, nueve de distintos países latinoamericanos y seis de otros países. Nos encontramos con una situación típica de los estudios sobre la cultura del subcontinente americano a partir de los noventa: a pesar de las denuncias de colonialismo en relación a Estados Unidos, son intelectuales norteamericanos o intelectuales de origen latino que han emigrado al norte por las pésimas condiciones políticas y culturales de sus respectivos países los que hablan sobre el tema. La Universidad de Pittsburgh, donde se instala el Instituto Internacional de Literatura Iberoamericana (IILI), se constituye en un centro fundamental desde el que irradian múltiples iniciativas. Mabel Moraña, tanto al frente de la Revista Iberoamericana, portavoz del citado Instituto, como de otras iniciativas editoriales en las que participa directamente o apoyando a sus promotores, cumple una función muy importante. No olvidemos que Hernán Vidal, otro gran impulsor del latinoamericanismo desde el norte, en este caso la Universidad de Minnesota (donde se sitúa el Institute for the Study of Ideologies and Literature), había reivindicado años antes "un área dedicada al estudio de la apropiación y creación de sistemas simbólicos en la cotidianidad de las culturas latinoamericanas, dentro de los departamentos universitarios de estudios literarios hispánicos" (Vidal, 1993c: 13). En Europa sólo es comparable a estos centros el Instituto de Literatura Iberoamericana de la Universidad de Berlín, que tiene en la editorial Iberoamericana-Vervuert su principal órgano de expresión, y a Alfonso de Toro a uno de sus más destacados y prolíficos "militantes".

Volviendo a la obra de Moraña, ésta se divide en ocho secciones en las que se intentan organizar todas las cuestiones abordadas. La más coherente es, sin duda, la primera, dedicada a "Globalización y Multiculturalismo", en la que tres autores representativos abordan la nueva situación marcada por la globalización y el multiculturalismo, términos ambos propios de los estudios estadounidenses puesto que desde el centro y el sur se preferirá hablar de transnacionalización y de estudios culturales o interculturales. Martín Barbero

\footnotetext{
${ }^{5}$ El carácter caótico de la obra de Moraña se desprende de la sistematización que hace Ileana Rodríguez (2000-2001: 170) de los conceptos de estudios culturales presentes en ella: "1) una ofensiva contra el poder monopolizador del canon literario y las bellas artes // 2) el intento de ampliar la cultura a otros dominios / / 3) el espacio donde se confecciona lo transdisciplinario // 4) el terreno donde se practica la desconstrucción derridiana y postmoderna de los esencialismos a fin de revalidar las diferencias multiculturales // 5) una agenda de colonización desde Estados Unidos // 6) la conciencia del quiebre disciplinario // 7) el lugar donde se manifiesta y explaya la crisis del sentido en la alta modernidad post-socialista // 8) el espacio donde se considera y discute la formación de las nuevas agencias sociales, de las identidades y subjetividades diversas más apropiadas a los tiempos nuevos postfordistas y postindustriales // 9) la conciencia de lo postmoderno / / 11) la reorganización de campos en torno a las teorías discursivas" .
} 
(2000), a pesar de que se doctoró en Ricoeur y Ladrière, según va evolucionando se deja influir por el pensamiento desconstructivista, lo que no le impide afirmar que la globalización disminuye y lo local redefine, por lo que ambos ofrecen nuevas concepciones de la nación y la identidad que, en contra de los pensadores postmodernos, el latinoamericano no cree que deban eliminarse de la agenda cultural. La preocupación por la educación, siempre un reto en los países latinoamericanos, le lleva a hablar de la creciente importancia de un pensamiento visual que se constituye en un nuevo paradigma de pensamiento que reestructura las relaciones entre la lógica (el orden discursivo) y la forma (lo visible), lo que agranda cada vez más la brecha existente entre profesores y alumnos en tanto que parten de formaciones e intereses distintos. García-Canclini utiliza un tono polémico y hasta sarcástico en su ensayo, "La épica de la globalización y el melodrama de la interculturalidad" (2000), en el cual contrapone la posición de un especialista norteamericano en estudios culturales a la de un antropólogo latinoamericano para terminar concluyendo con que las posiciones y perspectivas son plurales y divergentes en un sitio y en otro. Renato Ortiz también muestra sus desacuerdos con la actitud postmoderna: la diversidad y fragmentación, por sí solas, no bastan ni pueden considerarse un triunfo de la democracia; hay que establecer una "distinción cualitativa de las diferencias" (2000: 49).

Aunque muchas de las intervenciones vienen marcadas por intereses y posiciones típicamente estadounidenses: la subalternidad, el género, las fronteras, las metarreflexiones en torno al ser, metodología y operatividad de los mismos estudios culturales, aplicadas o no a casos de Latinoamérica, surgen voces que van a marcar claramente la diferencia con los estudios culturales norteamericanos. Esta diferencia es la reivindicación del carácter político e ideológico de todo estudio que se realiza sobre la cultura. En este sentido Beatriz Sarlo realiza una relectura de Raymond Williams (2000: 363-372) que pone de manifiesto la existencia de elementos de la tradición que pueden ser reincorporados al pensamiento de la época por su vigencia, y a la par recuerda que no todos los cultural studies se pueden identificar con los que se producen en Estados Unidos. Ricardo Kaliman habla de "Un muerto que habla: a favor de la crítica ideológica" (2000: 147-156), donde atribuye la supuesta "muerte de la ideología" al pensamiento metropolitano que sólo se ha fijado en fracasos puntuales y en una actitud que arrincona lo ideológico en el cajón de lo anacrónico e inoperante, pero no es así:

Desde el punto de vista de su productividad, esta muerte de la ideología, la muerte de esta ideología, no encuentra justificación. Sólo ciñéndonos al campo de los estudios culturales latinoamericanos, que es el más frecuentado, el modelo de la ideología se ha probado fructífero en la identificación y comprensión de procesos tan cruciales para comprender nuestra realidad como el desarrollo e institucionalización de la ciudad letrada, las incertidumbres y la consolidación de los estados nacionales o las variedades del indigenismo [...] (Kaliman, 2000: 149150).

Hernán Vidal no es menos contundente al respecto en su trabajo "Restaurar lo político, imperativo de los estudios literarios y culturales latinoamericanos" 
(2000: 139-146): "Hablo de restauración en la medida en que el colapso de los movimientos socialistas revolucionarios han desprestigiado el sentido de lo político. Al mismo tiempo es preciso poner límites a la afirmación postmodernista de que han perdido sentido todos los discursos de redención científica de la humanidad" (Vidal, 2000: 143) ${ }^{6}$. Vidal ve ahora con claridad que la transnacionalización de los estudios literarios americanistas se ha producido sin ningún tipo de diálogo intelectual (de ahí las fallas de tal transnacionalización), y es que "en la academia norteamericana se crean imágenes de Latinoamérica para fines de avance profesional que no guardan relación alguna con la realidad" (2000: 142). Los estudios culturales, en los que este autor depositaba todas sus ilusiones una década atrás, ahora se presentan como la alternativa de reciclamiento de críticos literarios desilusionados o descolocados.

Del 6 al 9 de septiembre de 2001 se celebra también en Pittsburgh, en el Instituto Internacional de Literatura Iberoamericana, el XXIII Congreso Internacional de la Latin American Studies Association (LASA). La misma Mabel Moraña, directora de publicaciones de la Revista Iberoamericana, hace posible la publicación de las Actas del encuentro en un número monográfico de 2003 coordinado por Alicia Ríos, Ana del Sarto y Abril Trigo que recibió el título "Los estudios culturales latinoamericanos hacia el siglo XXI". Celebrado el Congreso en Estados Unidos y pocos días antes del atentado contra el Word Trade Center, en la publicación del 2003 se deja entrever la preocupación por las consecuencias que en el ámbito cultural se sabe que va a tener aquel atentado, sobre todo el control y la represión cultural. Pero en lo que se refiere a los estudios culturales, el mismo encuentro había estado estructurado en torno a ejes temáticos que ponían de manifiesto las dificultades y sospechas que recaían sobre este ámbito de estudio ya en el siglo XXI. La primera mesa llevó el título "Los estudios culturales latinoamericanos: tradición y ruptura", y estuvo formada por Jesús Martín Barbero, Silviano Santiago, Carlos Monsiváis, Julio Ramos y Mabel Moraña. La segunda mesa, dedicada a "Los estudios culturales latinoamericanos: ¿institucionalización académica y/o intervención política?",

\footnotetext{
6 Estas preocupaciones son las que llevan a Hernán Vidal a formular su idea de la crítica literaria como defensa de los derechos humanos, idea desarrollada sobre todo en su libro Crítica literaria como defensa de los Derechos Humanos. Cuestión teórica (1993), en el que expone su propósito fundamental: "buscar el realineamiento de ideologemas teóricos para llegar así a un entendimiento de la literatura y de la crítica literaria en sí mismas como una historia de la creación y defensa de los derechos humanos" (1993: 9). Ni que decir tiene que, sin menospreciar las buenas intenciones inherentes al proyecto, se trata de una idea o excesivamente ambiciosa o improcedente, o ambas cosas a un tiempo, ya que la crítica literaria socio-histórica que este autor había defendido aborda el fenómeno literario como un producto histórico que puede, entre otras cosas, reflejar el respeto o la violación de los derechos humanos, pero de forma más o menos frecuente según la literatura y la época en la que se produce esa literatura, lo que impide, lógicamente, extender esta idea a la literatura y crítica literaria de todo tiempo o lugar. Por otra parte, existen muchas formas de compromiso activo en escritores, críticos y teóricos que no deben reducirse a una sola, pues ello sería forzar y simplificar una cuestión compleja y además muy delicada cuando nos referimos a países que viven situaciones políticas y sociales pésimas como son los latinoamericanos.
} 
contó con la presencia de Jean Franco, Renato Ortiz, Alberto Moreiras, George Yúdice y Román de la Campa. El volumen, en el que se incluyen también las intervenciones de autores tan representativos como John Beverly, Walter Mignolo, Daniel Mato o Marc Zimmerman, pone de manifiesto la trayectoria histórica de los llamados estudios culturales latinoamericanos en los ochenta y en los noventa, su relación con los cultural studies norteamericanos y su situación en el momento en que se impone la globalización: "cierta implosión del campo por saturación metateórica y metacrítica, lo que explicaría el actual sentimiento generalizado de incertidumbres, fatiga y desorientación", como diagnostican certeramente los coordinadores (Ríos, Sarto y Trigo, 2003: 327).

En efecto, el campo se estaba reconfigurando en ese momento, si no lo había hecho ya, pero nada dramático se escondía tras este hecho, sólo una evolución que ha desembocado en la constitución de otros campos de estudio que gozan de mayor coherencia teórica y epistemológica como se deduce de las propuestas de Daniel Mato, que aboga por lo que llama "prácticas intelectuales latinoamericanas en cultura y poder" (2003: 389 y ss.); Walter Mignolo (2003: 401 y ss.), cuyo pensamiento se cimenta cada vez más en el estudio de las geopolíticas del conocimiento, lo que le llevará a formular su peculiar teoría de la postcolonialidad; John Berverly (2003: 335 y ss.), que apuesta por el estudio del subalterno aun cuando el Grupo Latinoamericano de Estudios Subalternos había sido disuelto; George Yúdice, que sitúa los estudios culturales en "la encrucijada de la incertidumbre" (2003: 449 y ss.); y Alberto Moreiras (2003: 431y ss.), que habla incluso de "retirar la cultura" no sólo por la nueva situación que surge tras el 11-S, sino también porque:

\begin{abstract}
La ingenuidad fundamental o inaugural de los estudios culturales consiste en haber supuesto que el éxito político podría darse dentro de la estructura referencial del discurso académico, expeditivamente, sin apostar por un cambio de la racionalidad, sino poniendo la racionalidad heredada al servicio de la reforma en la articulación hegemónica del saber. Demasiado expeditivamente los estudios culturales entendieron lo político filocéntricamente, a la manera schmittiana, postulando que, si todo en política es cuestión de la relación de fuerzas entre amigo y enemigo, entonces bastaría con apilar material a favor del amigo, dotarle de palabra al amigo [...] (Moreiras, 2003.: 436).
\end{abstract}

Román de la Campa indaga en los motivos que han dado lugar a la situación que se discute en el Congreso:

\footnotetext{
Suele pensarse, o decirse, que todo se debe a la vulgarización de la cultura de masas, al abandono de la gran literatura o a la falta de más teoría, pero importa resistir simplificaciones. Vale repetir que el quiebre disciplinario procedía precisamente de la vanguardia teórica inspirada por los estudios literarios desde los setenta hasta los ochenta, pero esa radicalidad en potencia se desvía, queda sumida por la propia cultura global, la cual ya se muestra capaz de absorber el entorno conceptual de la diferencia, promover el multiculturalismo, nutrir la postmodernidad, compaginar el horizonte poscolonial y convivir armónicamente con la hipóstasis subalterna (Campa, 2003: 359).
} 
Las revisiones y relecturas a veces obsesivas de los estudios culturales no pueden acallar el canto del cisne, como tampoco pueden acallar las voces de los que siguen siendo fieles al estudio de ese rico ámbito constituido por la cultura latinoamericana (antes, durante y después de determinadas modas y tendencias) como Carlos Monsiváis (2003), que aún recela, a pesar de todo, de los estudios culturales entendidos como versión de los cultural studies. Ni la misma Mabel Moraña puede negar cierta derrota:

\begin{abstract}
Hasta ahora, el desmontaje de la ilustración y la modernidad ha sido mucho más efectivo que el del neoliberalismo y la globalización, y la crítica a la institucionalidad académica, la restricción disciplinaria y el exclusivismo humanístico mucho más productivos que las estrategias para reemplazarlos por proyectos verdaderamente democráticos en el interior de los cuales sobrevivan la independencia intelectual y las políticas de inclusión tanto como las posibilidades de conflicto, intercambio y pluralización. Si bien ya es evidente que los estudios culturales han triunfado en la tarea de colonizar el estatuto de las humanidades y las ciencias sociales, queda aún por probarse su verdadera capacidad de intervención y de interpelación política. Esto permitiría saber, una vez desmontada la modernidad, qué hacer con sus fantasmas (Moraña, 2003: 430).
\end{abstract}

Pero es que los estudios culturales estarían disueltos en tanto que no existe un proyecto común, sino una cantidad importante y una variedad de acercamientos o prácticas que Yúdice (2003: 450) resume así: “[acercamientos] mediáticos (Martín Barbero, Brunner, Landi), sobre culturas populares (García Canclini, Bonfill Batalla), sociológicos (Ortiz, Miceli, Lechner), antropológicos (Luis Ribeiro, Mato), marxistas (Dussel, Quijano), intelectuales y literarios (Rama, Ramos, Sarlo, Santiago, Schwarz), estéticos (Richard), filosóficos (Castro-Gómez), feministas (Lamas, Costa)". La cuestión es, para este autor, si hay que llamar a este conjunto de prácticas crítica cultural, según la propuesta de Nelly Richard, o estudios en cultura y poder, según la teoría de Daniel Mato.

\title{
3. Los estudios culturales frente a los estudios literarios
}

Haciendo un balance provisional, las consecuencias negativas de la irrupción de los estudios culturales para los estudios literarios son, entre otras, las que se derivan de los siguientes planteamientos:

1) Consideración de la literatura como una manifestación de la alta cultura o cultura de élite que ha gozado de enormes privilegios a lo largo de los siglos y que debe dar paso en este momento histórico a la baja cultura, esto es, cultura popular y sobre todo cultura de masas.

2) El discurso crítico literario, ligado a este concepto de lo literario, ha estado imbricado con el poder político y académico y, en consecuencia, no ha sabido o no ha querido ver los fenómenos que deben pasar a un primer lugar dentro de la jerarquía de conocimientos de nuestra época, fenómenos que serían los que nos definirían a nosotros mismos y a nuestro tiempo. 
3) La crítica y teoría literarias no son viables desde un punto de vista epistemológico porque, o bien se centran en métodos obsoletos del pasado (estructuralismo, historiografía literaria, etc.), o bien en corrientes de procedencia imperialista, ya sea Europa (postestructuralismo, desconstrucción, etc.) o Estados Unidos (postmodernismo, comparatística, etc. $)^{7}$.

Lo que se ignora es que frente a los estudios literarios tradicionales existen otros estudios literarios que en modo alguno pasan por alto toda la problemática social, histórica e ideológica que surge en las últimas décadas del siglo XX, cuando la irrupción de una nueva matriz histórica (ya se llame postmodernidad, era del conocimiento, época del capitalismo avanzado, sociedad digital o de otra forma, no vamos a entrar ahora en problemas terminológicos) es ya incuestionable. Los estudios literarios siempre han sido hijos de su propio tiempo, y el diálogo ha estado abierto durante todo el siglo XX: con la lingüística, el estructuralismo, el psicoanálisis, la historia, la sociología, la filosofía..., y la cultura. Porque también en Europa existe una amplia tradición de teoría y crítica cultural (ver, sobre esta cuestión, Pulido Tirado, 2003) que no puede ignorarse aun cuando la hegemonía en los medios académicos se atribuya siempre a los estudios culturales, primero británicos y luego norteamericanos, canadienses y australianos principalmente.

En contra de las valoraciones de los antólogos de turno, si valoramos la ausencia de estudios culturales en Europa occidental (con la excepción ya citada de Gran Bretaña en donde, por otra parte, no nacen ni se desarrollan en contra de la literatura ni frente a ella, baste con recordar el nombre de uno de sus más importantes representantes, Raymond Williams) a la luz de las corrientes de crítica de la cultura que han convivido en perfecta armonía con estudios literarios de distinto signo, entendemos que no se haya sentido la necesidad de crear o practicar unos estudios culturales al estilo norteamericano porque para nosotros estudiar la cultura popular y la cultura de masas no es incompatible con el estudio de la literatura, pues en ambos casos nos encontramos con productos históricos que, aunque se manifiestan de distinta forma, son complementarios y responden a una misma realidad, a cuya complejidad no nos podemos acercar mediante el método de la eliminación. Por otro lado, corrientes como la semiótica de la cultura tienen una envergadura especial en este punto, y no todos los autores latinoamericanos lo ignoran, baste como botón de muestra la obra de Manuel Alcides Jofré titulada de forma muy significativa Tentando vías: semiótica, estudios culturales y teoría de la literatura (1995). En ella el autor se manifiesta con claridad:

\footnotetext{
${ }^{7}$ Y no voy a entrar a comentar el inestimable servicio que están haciendo los estudios culturales norteamericanos a la derecha y a su promoción de lo políticamente correcto al tiempo que se institucionalizan y, en la universidad, ponen de manifiesto su enorme rentabilidad ideológica y académica. Sobre ésta y otras cuestiones vinculadas al texto paradigmático de los cultural studies norteamericanos, la antología publicada por L. Grossberg, C. Nelson y A. Trichler (1992), erige su visión crítica Jameson (1996).
} 
Hoy en día el ejercicio literario es un fenómeno no sólo posible de ser analizado a partir de diferentes metodologías sino que también puede ser entendido como parte de grandes estrategias culturales que dinámicamente tienen lugar en toda sociedad. Como una práctica de las relaciones sociales, la literatura y su estudio no puede ser aislada de su contexto cultural porque la literatura constituye epistemas, crea visiones de mundo y expresa formas culturales; todo esto, mientras asume una estructura comunicativa en su funcionamiento. Así, comunicación, cultura, educación y estética son áreas de la vida humana que están vinculadas al fenómeno literario y a su teorización (Jofré, 1995: 6).

Si el trasfondo histórico de toda la problemática que estamos tratando aquí es la revolución tecnológica que da lugar a la sociedad actual, este hecho se traduce, en nuestro campo, en un problema en torno a los valores. Beatriz Sarlo, representante de los estudios culturales en Argentina, y denostada por sus compañeros en tanto que no ha dudado en poner de manifiesto sus deudas con la Escuela de Frankfurt o Louis Althusser, ha apuntado directamente al centro de la cuestión:

El lugar de la literatura está cambiando. La popularidad creciente de los estudios culturales, que dan trabajo a cientos de críticos literarios reciclados, es una respuesta a estos cambios. Sin embargo hay algo que la crítica literaria no puede distribuir blandamente entre otras disciplinas. Se trata de la cuestión de los valores estéticos, de las cualidades específicas del texto literario (Sarlo, 1997: 32).

En efecto, sin pretender negar la legitimidad de estudio de una telenovela o de la cultura de una tribu urbana en tanto que significativo de una realidad social y de una determinada época histórica, ¿puede situarse este estudio a la altura de otro que tiene por objeto la obra de Borges?, ¿qué relación debemos establecer entre la telenovela y la cultura urbana con la narrativa de un escritor universal? En una sociedad de consumo la autoridad cultural de la literatura viene en gran medida determinada por el uso que hacen de ella sus consumidores $\mathrm{y}$, aunque se escribe, se escribe mucho, la gran masa de consumidores no está con la literatura. Y ello por razones evidentes: la literatura ya no es un modelo o práctica que conforme la identidad nacional; es en la Revolución cubana, cuando literatura y compromiso van íntimamente ligados, cuando surge la idea de que la transculturación estaba conectando con la ideología cultural del mestizaje, más amplia, que podía servir de base a la identidad latinoamericana. No olvidemos que Ángel Rama, en La ciudad letrada (1984), pone de manifiesto que la literatura escrita es una práctica constitutiva de las élites, lo que sin duda repercute sobre una población de bajo nivel cultural -cuando no analfabeta- que, tras el proceso de democratización que sigue a la caída de las dictaduras, reivindica un lugar propio en el poder y el saber de unos países en los que las desigualdades y las injusticias económicas, políticas e históricas no parecen dar más que ocasionales respiros.

A pesar de lo impopular de esta postura, existen autores que no dudan en seguir reivindicando el ideal de ciudadano letrado como Beatriz Sarlo. Otros autores realizan apuestas de compromiso, como es el caso de John Beverly, teórico de la ya llamada literatura testimonial, quien, frente a los estudios culturales, propone como alternativa "problematizar la literatura en el mismo 
acto de escribirla y enseñarla dentro de su estamento" (Beverly, 1995: 38), propuesta insuficiente ya que allí donde se establecen los estudios culturales se deja progresivamente de enseñar literatura y, situada ésta al margen de un lector potencial de amplio espectro, los escritores escriben para una minoría sumamente cualificada que, en muchas ocasiones, forma parte del circuito literario más estricto: los mismos escritores, críticos o teóricos. Como ha estudiado Beatriz Sarlo, el final del siglo $X X$ ha asistido a una desterritorialización cultural que ha impulsado las representaciones particularistas frente a la razón universal y unificadora de la modernidad -la retórica del particularismo se hace patente en distintos discursos postmodernos, entre ellos los estudios culturales, donde ocupa un lugar destacado-. La crisis del final de siglo se traduce, a juicio de esta autora, en:

La crisis de las ideas de cambio como progreso que modifica la sociedad en todos sus puntos comprometiendo la acción y el destino de la mayor parte de sus miembros (la crisis de la idea 'total' de cambio; la crisis de las vanguardias y de los valores estéticos de la modernidad y, con ella, la de una continuidad cultural conflictiva; la crisis de la figura clásica del intelectual, que sigue a la reestructuración de las relaciones entre niveles culturales a partir de la organización massmediática de la dimensión simbólica (Sarlo, 1993: 2) $)^{8}$.

La debilitación del principio de legitimidad y universalidad del juicio intelectual no sólo tiene repercusiones en el ámbito político, sino también en el estético, en el que el particularismo conduce a una crisis de la representación en tanto que cada grupo habla por sí mismo y no hay voluntad de emprender ningún proyecto a favor de los intereses generales. Este particularismo encuentra un lugar óptimo de acomodo en la cultura de los medios de comunicación de masas que ya ocupa un lugar importante en la cultura popular, pero esta cultura no parece tener una estética que pueda competir con la vanguardista. En este sentido, basándose en el silencio o complicidad de los en otros tiempos intelectuales críticos, habla Beatriz Sarlo de neopopulismo intelectual.

La literatura, sin embargo, no puede diluirse o perderse en la cultura de masas porque ahora más que nunca se ha constituido en una práctica que exige una elevada formación (literaria y cultural) tanto al emisor como al receptor, y que no se confunde con otras (el fenómeno de los best-sellers, tan típicamente norteamericano, es un caso aparte en el que no voy a entrar aquí). Lo que parece en todo punto imposible es querer que la literatura tenga la popularidad de un programa de televisión de gran audiencia. La cuestión es cómo lograr que convivan ambos tipos de estudios: los culturales y los literarios, y que lo hagan además con coherencia, siendo conscientes de su función social y sus respectivos objetos de conocimiento. El peligro surge del que ahora se muestra

\footnotetext{
8 Sobre la polémica entre Beatriz Sarlo y Horacio González sobre la función del intelectual, muy significativa de las preocupaciones de esta época, ver Nelly Richard (2000). Hay que tener en cuenta, en cualquier caso, que la idea que subyace en todos estos debates es la teoría de Gramsci sobre intelectuales orgánicos e intelectuales tradicionales (ver Gramsci, 1960).
} 
como discurso dominante (aunque plural, fragmentado e indefinido en muchos casos): los estudios culturales; esta situación permite a sus cultivadores tomar la academia a la par que desplazar de esa misma academia a los estudios literarios, hecho de consecuencias insospechadas para el futuro de la literatura ya que sin una formación de los lectores desde edad temprana el círculo se irá reduciendo cada vez más.

En el seno de los estudios literarios latinoamericanos la relación que se estaba produciendo entre estudios culturales y estudios literarios no podía ignorarse. En 1996 Mabel Moraña dirige un número monográfico de la Revista Iberoamericana dedicado a la "Crítica cultural y teoría literaria latinoamericana", pero sólo en teoría ya que se habla de crítica cultural y sobre todo de estudios culturales, la teoría literaria (crítica, reflexiones generales) sale peor parada.

Años después Adriana J. Bergero y Aldo Ruffinelli vuelven a intentar desentrañar el tema en otro número monográfico de otra revista de gran prestigio, Nuevo Texto Crítico. El título aquí se formula en forma de interrogante, lo que señala las dudas insertas en el origen mismo del proyecto: “¿Cuál sería la relación entre los estudios literarios y el análisis cultural / estudios culturales?" (2000-2001). Adriana J. Bergero, en el artículo que sirve de introducción al número, "Estudios Literarios / Culturales. Disciplinariedad y nuevas configuraciones", es la que más claramente aborda el tema. Bergero parte de que en ese momento se está viviendo una reconfiguración del lugar de la razón crítica del intelectual, de la cultura, de la academia y de los estudios literarios; es entonces, en un ambiente de confusión y cambio, cuando surgen los estudios culturales: "Este nuevo emplazamiento implicaba la reconfiguración teórica de la 'cultura' como espacio de multidisciplinariedad, y su análisis, como un pasadizo a través de los objetos de estudio, agentes, praxis sociales y campos culturales" (Bergero, 2000-2001: 6). Los dos primeros pasos a seguir fueron, primero, rechazar la oposición entre cultura culta y popular o alta y baja cultura; el segundo, ver la identidad y la cultura no desde una perspectiva estática sino como procesos de transformación y reinvención permanentes que debían ser abordados siempre desde una perspectiva transdisciplinaria. En Latinoamemérica la búsqueda de otro lugar desde el que abordar la situación de periferia, residualidad y desvíos había llevado tempranamente a autores como Antônio Cândido, Ángel Rama o Cornejo Polar a replantearse qué es la literatura. Los estudios culturales, postcoloniales y subalternos parecen responder en gran medida a las incertidumbres y ofrecer instrumentos con los que acercarse a problemáticas tan candentes como las relaciones de poder existentes entre metrópoli occidental y periferia, resistencia y reconversión de lo popular y nacional en cultura global de masas, preocupaciones también destacadas de los estudios latinoamericanistas.

Los estudios culturales aparecen, pues, marcados por la pluralidad, la heterogeneidad y la transdisciplinariedad en Latinoamérica, razón que justifica, a juicio de Bergero, el surgimiento del debate a nivel académico, debate que se puede resumir en tres cuestiones fundamentales:

1.- Los estudios culturales consideran la literatura como obsoleta y desmantelada toda vez que ha perdido su autonomía estética y disciplinaria, lo 
que provoca el rechazo de quienes abogan por la existencia de valores estéticos y de una función crítica y una especificidad de la institución literaria.

2.-La filiación geopolítica y cultural de los estudios culturales, ya sea británica o norteamericana, lleva a su rechazo en tanto que representaría un neocolonialismo cultural inaceptable.

3.- Desde la perspectiva de la educación universitaria se detectan presiones para internacionalizarla o muticulturalizarla convirtiéndola así en un aparato complementario de los tratados transnacionales neoliberales. En Estados Unidos esto se ha traducido en un aumento de los cursos de lengua y cultura en detrimento de los estudios literarios; hecho que estudian José Monleón y Ana del Sarto en el mismo número de Nuevo Texto Crítico.

En suma, la polémica sigue, pero la irrupción y desarrollo de los estudios culturales, que cuentan a estas alturas con tantos cultivadores como detractores, no han logrado erradicar los estudios literarios, pues éstos se han sometido a un proceso de revisión crítica que los ha conducido a una renovación de metodologías y planteamientos básicos en torno al fenómeno literario que ahora hay que considerar, más que nunca, como fruto de una época histórica concreta.

\section{BIBLIOGRAFÍA}

BERGERO, A. (2000-2001): “Estudios Literarios / Estudios Culturales. Disciplinariedad y nuevas configuraciones académicas", en A. Bergero y J. Rufinelli (eds.) (20002001): 5-22.

BERGERO, A. y RUFFINELLI, J. (eds.) (2001-2001): ¿Cuál sería la relación entre los estudios literarios y el análisis cultural / estudios culturales?", Nuevo Texto Crítico, 25-28 [monográfico].

BEVERLY, J. (1995): “Hay vida más allá de la literatura?”, Estudios. Revista de Investigaciones Literarias (Caracas), 6, jul.-dic.: 23-40.

BEVERLY, J. (1996): "Estudios culturales y vocación política", Revista de crítica cultural (Santiago de Chile), 12, julio.

BEVERLY, J. (2003): “La persistencia del subalterno", en A. Ríos, A. Sarto y A. del Trigo (eds.) (2003): 335-342.

CAMPA, R. DE LA (1996): “Latinoamérica y sus nuevos cartógrafos: discurso poscolonial, diásporas intelectuales y enunciación fronteriza", en M. Moraña (ed.) (1996): 697-718.

CAMPA, R. DE LA (2003): “Embajadas de la fuga y pensadores académicos", Revista Iberoamericana (Univ. Of Pittsburgh, Instituto Internacional de Literatura Iberoamericana), LXIX, 203: 355-360, recogido en A. Ríos, A. del Sarto y A. Trigo (eds.) (2003): 355-360.

CASTRO GÓMEZ, S. y MENDIETA, E. (coords.) (1998): Teorías sin disciplina. Latinoamericanismo, poscolonialidad y globalización en debate, México, University of San Francisco / Miguel Ángel Porrúa, en: <http://ensayo.rom.uga.edu/critica/teoria.castro/> (consultado en agosto de 2006)

CERTEAU, M. DE (1984): The Practice of Everyday Life, Berkeley, University of California Press. 
FRANCO, J. (1994-1995): "El ocaso de la Vanguardia y el auge de la crítica", en C. Rincón y P. Schumm (eds.) (1994-1995): 11-22.

GARCÍA CANCLINI, N. (1989): Culturas híbridas. Estrategias para entrar y salir de la modernidad, México, Grijalbo, Trad. al inglés en 1995: Hybrid Cultures: Strategies for Entering and Leaving Modernity. Trad. de Christopher L. Chiappari y Silvia L. López, Prefacio de Renato Rosaldo, Minneapolis, Minnessota UP.

GARCÍA CANCLINI, N. (1991): “Los estudios culturales de los 80 a los 90: perspectivas antropológicas y sociológicas en América Latina", Iztapalapa. Revista de Ciencias Sociales y Humanidades (México), 24: 9-26.

GARCÍA CANCLINI, N. (1995a): "El diálogo norte-sur en los estudios culturales", Introducción la edición en inglés de García Canclini (1995b), Edición en español en <www.cholanautas.edu.pe $>$ (consultado en agosto de 2006).

GARCÍA CANCLINI, N. (1995b): Consumidores y ciudadanos: conflictos multiculturales de la globalización, México, Grijalbo.

GARCÍA CANCLINI, N. (1997): “El malestar en los estudios culturales", Fractal (México), 6, julio-septiembre, II: 45-60. Versión en <http://www.fractal.com.mx/6cancli.html> (consultado en agosto de 2006)

GARCÍA CANCLINI, N. (2000): "La épica de la globalización y el melodrama de la interculturalidad", en M. Moraña (ed.) (2000): 35-48.

GRAMSCI, A. (1960): Los intelectuales y la organización de la cultura, Traducción de Raúl Sciarreta, Buenos Aires.

GROSSBERG, L., NELSON, C. y TREICHLER, P. A. (eds.) (1992): Cultural Studies, New York, Routledge.

JAMESON, F. (1996): Teoría de la postmodernidad, Trad. de Celia Montolío Nicholson y Ramón del Castillo, Madrid, Trotta.

JOFRÉ, M. A. (1995): Tentanto vías: semiótica, estudios culturales y teoría de la literatura, Santiago de Chile / Ecuador: Universidad Católica Blas Cañas / Universidad Andina Simón Bolívar.

KALIMAN, R. J. (2000): “Un muerto que habla: en favor de la crítica ideológica”, en M. Moraña (ed.) (2000): 147-156.

KOKOTOVIC, M. (2000): "Hibridismo y desigualdad: García Canclini ante el neoliberalismo", Revista de Crítica Literaria Latinoamericana, 52, 2do. Semestre: 289-300.

MARIACA, G. (1994-1995): “La modernidad y la crítica literaria latinoamericana”, en C. Rincón y P. Schumm (eds.) (1994-1995): 147-163.

MARTÍN-BARBERO, J. (2000): “Globalización y multiculturalidad: notas para una agenda de investigación”, en M. Moraña (ed.) (2000): 19-34.

MATTERLART, A. y NEVEU, É. (2003): Introducción a los estudios culturales, Trad. de Pilles Multigner, Barcelona, Paidós, 2004.

MATO, D. (ed.) (2002): Estudios y otras prácticas latinoamericanas en cultura y poder. Caracas: CLACSO. Los artículos de este libro están disponibles en <http://www.globalcult.org.ve/ >

MATO, D. (2003): "Prácticas intelectuales latinoamericanas en cultura y poder: sobre la entrada en escena de la idea de 'Estudios Culturales Latinoamericanos' en un campo de prácticas más amplio, transdisciplinario, crítico y contextualmente referido", en A. Ríos, A. del Sarto y A. Trigo (eds.) (2003): 389-400.

MIGNOLO, W. (1996): "Posoccidentalismo: las epistemologías fronterizas y el dilema de los estudios (latinoamericanos) de áreas", Revista Iberoamericana, LXII, 176177, julio-diciembre: 679-696 [monográfico editado por Mabel Moraña], recogido en S. Castro-Gómez y E. Mendieta (coords.) (1998): 31-58. 
MIGNOLO, W. (2003): "Los estudios culturales: geopolítica del conocimiento y exigencias / necesidades institucionales", en A. Ríos, A. del Sarto y A. Trigo (eds.) (2003): 401-415.

MONSIVÁIS, C. (2003): “De cómo vinieron los estudios culturales y a lo mejor se quedan “, en A. Ríos, A. del Sarto y A. Trigo (eds.) (2003): 417-424.

MORAÑA, M. (ed.) (1996): Crítica cultural y teoría literaria latinoamericana, Revista Iberoamericana, LXII, 176-177, julio-diciembre [monográfico].

MORAÑA, M. (2000): “Introducción”, en M. Moraña (ed.) (2000).

MORAÑA, M. (ed.) (2000): Nuevas perspectivas desde / sobre América Latina: El desafío de los estudios culturales, Pittsburgh, Universidad de Pittsburgh, Instituto Internacional de Crítica Iberoamericana, $2002^{2}$.

MOREIRAS, A. (2003): “Retirar la cultura”, en A. Ríos, A. del Sarto y Abril Trigo (eds.) (2003): 41-440.

ORTIZ, R. (2000): “Diversidad cultural y cosmopolitismo”, en M. Moraña (ed.) (2000): 649-655.

PULIDO TIRADO, G. (2003): “Cuando la cultura popular tomó la calle y la academia. Sobre el lugar cambiante de los estudios culturales", en G. Pulido Tirado (ed.) (2003): Estudios culturales, Jaén, Universidad de Jaén: 109-135.

RAMA, Á. (1984): La ciudad letrada, Hannover, Eds. Del Norte.

RICHARD, N. (2000): “Un debate latinoamericano sobre práctica intelectual y discurso crítico", Revista Iberoamericana, LXVI, 193, oct-dic: 841-850.

RÍOS, A. (2000-2001): “Los Estudios Culturales Latinoamericanos (jsigamos el debate!)", en A. Bergero y J. Ruffinelli (eds.) (2000-2001): 161-168.

RÍOS, A., SARTO, A. Del y TRIGO, A. (2003): “Presentación”, en A. Ríos, A. del Sarto y A. Trigo (eds.) (2003): 323-331.

RÍOS, A., SARTO, A. Del y TRIGO, A. (eds.) (2003): Los estudios culturales latinoamericanos hacia el siglo XXI, Revista Iberoamericana, LXIX, 203, abril-julio [monográfico].

RINCÓN, C. (1978): El cambio en la noción de literatura y otros estudios de teoría y crítica latino-americana, Lima, Instituto Colombiano de Cultura.

RINCÓN, C. (1994-1995): "Entre las crisis y los cambios: un nuevo escenario", en C. Rincón y P. Schumm (1994-1995): 5-10.

RINCÓN, C. y SCHUMM, P. (1994-1995): Crítica literaria hoy. Entre las crisis y los cambios: un nuevo escenario, Nuevo Texto Crítico, 14/15 [monográfico].

RÍOS, A. (2002): "Los estudios culturales y el estudio de la cultura en América Latina", en D. Mato (ed.) (2002).

RODRÍGUEZ, I. (2000-2001): “'Estudios culturales': Quiebres disciplinarios, cambios del oficio crítico y crisis del sentido en la época post-socialista", en A. Bergero y J. Ruffinelli (eds.) (2000-2001): 169-181.

ROWE, W. (1994-1995): “La crítica cultural: problemas y perspectivas”, en C. Rincón y P. Schumm (1994-1995): 37-48.

SARLO, B. (1993): “¿Arcaicos o marginales? Situación de los intelectuales en el fin de siglo", Punto de vista, 47, diciembre: 1-5.

SARLO, B. (1997): “Los estudios culturales y la crítica literaria en la actual encrucijada valorativa", Revista de Crítica Cultural, 15: 32-38. En

$<$ www.neac.com/LaIslaEnPeso/num07/mirada.htm> (consultado en agosto de 2006)

SARLO, B. (2000): "Raymond Williams: una relectura”, en M. Moraña (ed.) (2000): 363372.

SPIELMANN, E. (1996): “'Nosotros habíamos hecho Estudios Culturales mucho antes de que esta etiqueta existiera'. Entrevista con Jesús Martín-Barbero", Dissens (Pontificia Universidad Javeriana), 3, 1997: 47-53. En 
$<$ http://www.javeriana.edu.co/pensar/Rev33.html > (consultado en agosto de 2006).

VIDAL, H. (1983a): “Introducción”, en H. Vidal (ed.) (1983): 1-8.

VIDAL, H. (1983b): "Para una redefinición culturalista de la crítica literaria latinoamericana", en H. Vidal (ed.) (1983): 121-132.

VIDAL, H. (1993a): Crítica literaria como defensa de los Derechos Humanos, New Jersey, Juan de la Cuesta.

VIDAL, H. (1993b): "The Concept of Colonial and Postcolonial Discourse: A Perspective from Literary Criticism", Latin American Research Review, 28. 3: 113119.

VIDAL, H. (1993c): “Introducción”, en H. Vidal (ed.) (1993).

VIDAL, H. (1996): “Los derechos humanos, hermenéutica para la crítica literaria y los estudios culturales latinoamericanistas: informe de una experiencia”, en M. Moraña (ed.) (1996): 719-731.

VIDAL, H. (2000): "Restaurar lo político, imperativo de los estudios literarios y culturales latinoamericanistas", en M. Moraña (ed.) (2000): 139-146.

VIDAL, H. (ed.) (1983): El significado socio-politico de la crítica actual (España, Portugal, Latinoamérica, Luso-África), Ideologies and Literature, 4, 16 [monográfico].

VIDAL, H. (ed.) (1993): Hermenéuticas de lo popular, Minneapolis, University of Minnesota, Institute for the Study of Ideologies and Literature.

WALSH, C. (2003): “QQué saber, qué hacer y cómo ver?”. En WALSH, C. (ed.) (2003): 11-28.

WALSH, C. (ed.) (2003): Estudios culturales latinoamericanos. Retos desde y sobre la región andina, Quito, Universidad Andina Simón Bolívar / Eds. Abya Yala.

WILLIAMS, R. (1976): Keywords. London: Fontana (sv. Cultura), traducido al español por Tomás Austin M., y en:

$<$ http://www.infoamerica.org/teoria/articulos/williams1.htm>

(consultado en agosto del 2006)

YÚDICE, G. (2000): “La globalización y el expediente de la cultura”, RELEA (Caracas), 10.

YÚDICE, G. (2002): “Contrapunteo estadounidense / latinoamericano de los estudios culturales", en D. Mato (coord.) (2002).

YÚDICE, G. (2003): "Los estudios culturales en la encrucijada de la incertidumbre", en A. Ríos, A. del Sarto y A. Trigo (coords.) (2003): 449-464. 